\title{
The Range of Prey Size of the Royal Bengal Tiger of Sundarbans
}

\author{
Subrat Mukherjee $^{1}$ and Neera Sen Sarkar ${ }^{2}$ \\ ${ }^{1}$ Sundarbans Tiger Reserve, Institute of Environmental Studies and Wetland Management, DD-24, Sector-I, Salt Lake City, \\ Kolkata, West Bengal 700 064, India \\ ${ }^{2}$ Department of Botany, University of Kalyani, Nadia District, Kalyani, West Bengal 741235, India
}

Correspondence should be addressed to Neera Sen Sarkar; neerashen@yahoo.co.in

Received 25 May 2013; Revised 1 October 2013; Accepted 15 October 2013

Academic Editor: Winn J. Huang

Copyright (C) 2013 S. Mukherjee and N. Sen Sarkar. This is an open access article distributed under the Creative Commons Attribution License, which permits unrestricted use, distribution, and reproduction in any medium, provided the original work is properly cited.

\begin{abstract}
Relatively little is known about the feeding habit of the Royal Bengal Tiger of Sundarbans and the relative biomass of individual prey base species that the predator consumes during each kill. This is the first attempt to collect such data from the study area. Data sets of two phases have been used. Identification of undigested remains of 214 tiger scat samples was carried out. A comparison with Sundarbans tigers in zoo has been made. In its natural habitat, the tiger consumes more of spotted deer, followed by wild boar, rhesus monkey, and water monitor. Though the tiger consumes a relatively low proportion of small prey species to meet its dietary requirements, it gains importance in the present perspective. Significant increase is noted in the relative number of prey species consumed in the second phase, which correlates well with increased prey availability. Hypotheses formulated to find the difference in prey biomass and relative number of prey consumed have been tested statistically. A significant difference in terms of relative number of prey consumed only was derived which has been qualitatively correlated with the positive effect of increased vigilance, as revealed by secondary data, on conserving tiger habitat vis-a-vis the increased prey availability in Sundarbans.
\end{abstract}

\section{Introduction}

As with all other organisms, the tiger's diet is a fundamental aspect of its ecological niche. Quantifying diets has long been and continues to be one of the first steps in studying a species' basic ecology as discussed by Sih and Christensen [1]. For the community ecologist, forager diets potentially play a central role in determining the predator-prey interactions and dynamics of competition between species [2, $3]$. The availability and range of diet play a pivotal role in determining the dynamics of competition at inter- and intraspecific levels, predator-prey interactions, and other community interactions. An understanding of diets, and ideally, an ability to predict diet shifts in response to changes in prey biomass or prey availability are thus major issues, especially in conservation and management affairs.

The tiger is always found to be associated with large mammalian herbivorous prey species in all its habitat ranges across the globe. These include wild buffalo (Bubalus bubalis), gaur
(Bos gaurus), nilgai (Boselaphus tragocamelus), swamp deer (Cervus duvaucelii), sambar (Rusa unicolor), barking deer (Muntiacus muntjak), spotted deer (Axis axis), and wild boar (Sus scrofa) [4-8]. But according to Schaller [4], occasionally they have been found to predate on other carnivores like leopards (Panthera pardus), sloth bears (Melursus ursinus), civet cats, and small vertebrate species like frogs also. The tiger is reported to have failed to survive in areas wherever these key prey species including large ungulates and primates have been exterminated [9], although it is known that most of the large mammals change their food habits according to their physiological as well as reproductive state. Several hypotheses have been proposed to explain prey selection by predators. These hypotheses at times take into account ultimate causal factors such as energetic benefits and costs involved $[10,11]$ and also proximate mechanisms of selection such as prey vulnerability [12-14]. Tigers on an average, like most other cats, take more number of preys, which are generally less than their own body size $[15,16]$ but are also reported to 
consume prey species larger than themselves, when largesized preys are available in higher densities [8]. Hence, prey selection of tigers in any area is ultimately the cumulative effect of different ecological, behavioral, and habitat factors which delineates the availability and vulnerability of prey species at any particular time [17].

Studies have described systems where extinction of apex predators has caused trophic cascades that have influenced community structure and ecosystem $[18,19]$. Because inferences are frequently drawn from food-habit studies of predators to predict stability of an ecosystem with particular reference to prey-predator dynamics, it is important that results from such studies accurately describe the diet. Faeces of wild animals are the most evident and most easily recognizable signs of their presence [20]. Major carnivores are at an advantage in this regard because they normally feed on such animals which are easily recognizable in their droppings which consist of partly digested material and undigested parts of such animals and occasionally plants. The fecal components may include bones, teeth, claws, scales, feathers, and plant tissues as well as mucus, epithelial cells, and a significant amount of living and dead bacteria. Because tiger is a specialized hunter, its breeding success, organization, and land tenure system are affected by the availability composition and distribution (temporally and spatially) of suitable prey. Therefore, emphasis is needed on understanding the predator-prey relationship. It is also important to study how the tigers respond to the variable environments.

The tiger of Sundarbans is the World-renowned Royal Bengal Tiger (Panthera tigris tigris). Sundarbans tiger is different from any other tiger in the country and the world because of its adaptability to the unique mangrove habitat. Their behaviour is largely individual specific and cannot be generalized and is also not replicable from the studies made on other tigers of the world or the country, even in Sundarbans itself. Much used word of "aberrations" is actually its adaptation to a hostile land which renders it perpetually under stress. Tigers in Sundarbans eat fish and crabs, can swim very fast in the big rivers even up to the speed of $13 \mathrm{~km} / \mathrm{hr}$., climb trees, drink salty water, take their prey in broad daylight, prey upon human beings, and do not have any common preying behaviour. The tiger pugmarks are seen everywhere in the forest though the tiger itself is not so visible. These added with the hostile habitat make Sundarbans not an ideal place to study tigers. The present paper deals with the study of food preferences, availability of prey, and the effect that increased protection in the area by the Department of Forest through its different measures over the two phases of study has had on the Panthera tigris tigris from the Sundarbans Tiger Reserve (STR).

\section{Materials and Methods}

2.1. Study Area. The STR within $88^{\circ} 42^{\prime} 1.703^{\prime \prime} \mathrm{E}-$ $89^{\circ} 6^{\prime} 33.573^{\prime \prime} \mathrm{E}$ and $22^{\circ} 12^{\prime} 54.39^{\prime \prime} \mathrm{N}-21^{\circ} 33^{\prime} 17.986^{\prime \prime} \mathrm{N}$ is one of the first tiger reserves amongst India's nation-wide network of 39 tiger reserves, wherein, India's globally renowned conservation scheme "Project Tiger" was initiated on 23rd
December, 1973. The initial demarcation of "Core Area" was declared as "national park" since 1984. Under the present demarcation (since 2007) of this protected area, an area of 1699.62 sq. km has been declared as "core area" or "critical tiger habitat" with a buffer area of 885.27 sq. Km (Figure 2). The adjoining forest area under the 24 Parganas (South) Division covering an area of $1500 \mathrm{sq}$. $\mathrm{km}$ also acts as buffer area to the STR. Within the buffer area the Sajnekhali Wildlife Sanctuary is located covering an area of $362.42 \mathrm{sq}$. Km. The importance of this area lies in the recognition of the area as a world heritage site/property by the UNESCO. Project Tiger is a comprehensive natural ecosystem conservation project aiming to promote conservation of the natural ecosystem by mitigating man-induced limiting factors and to bring it as close to natural functioning as possible. The region has a typical tropical climate, with an average annual rainfall of $1920.30 \mathrm{~mm}$ and an average temperature range of $20^{\circ} \mathrm{C}$ to $34^{\circ} \mathrm{C}$ round the year. The expanse is also characterized by its high humidity, the average humidity being just over 80 per cent and more or less uniform throughout the year. During the months of January and February, dense ground mists occur in the early morning. The area is characterized by dense mangrove vegetation with Avicennia marina Forssk. (Vierh.), Avicennia alba Blume, Avicennia officinalis L., Sonneratia apetala Buch.-Ham., Rhizophora mucronata Lam., Bruguiera gymnorhiza (L.) Lam., Excoecaria agallocha L., Ceriops decandra (Griff.) Ding Hou, Xylocarpus granatum Koenig, Xyloarcarpus mekongensis Pierre., Phoenix paludosa Roxb., Heritiera fomes Buch.-Ham., Aegialitis rotundifolia Roxb., Aegiceras corniculatum (L.) Blanco, Nypa fruticans Wurmb, and a few others forming the major vegetation components. The entire area is covered by soft, ill-consolidated slushy and sandy soil substratum with high salt and water content is regularly under the influence of tidal regimes; the soil, also characterized by low oxygen content and abundant hydrogen sulphide, is comparatively young, very fine grained, and typically semifluid; some parts contain abundant humus, whereas some are rich in calcareous materials brought in from the sea in the silt by the tides. Only the upper layers of the soil in such areas are found to be well oxygenated.

2.2. Methodology. The tiger diet was reconstructed through analysis of the scat. Tiger scats were collected whenever encountered during the two phases of the study (1999-2001 and 2008-2010). These scats were identified on the basis of associated signs and tracks and also size and appearance. The exercise had its advantage as the habitat under study is not home to any major same-trophic occupant competing for similar resources, sampling could be done without confusion but was extremely difficult in the hostile environmental situation of the study area. While collecting, all the available boluses were collected as a single sample and mixed randomly. Collected scats were washed with water followed by a dilute acid. Subsequently, the undigested remains such as hair, bones, hooves, quills, nails, and teeth of the prey consumed were separated for prey base species identification. The hair, bones, hooves, quills, nails, and teeth were identified on the basis of their general appearance like colour, length, width, 
medullary structure, and cuticle pattern. Quantification of the diet was based on both frequency of occurrence (proportion of total scats in which each item was found) and percent of occurrence (number of times a specific item was found as a percentage of all items found).

2.3. Data Analysis and Interpretation. The frequencies of prey species remains, which can be identified in scats, do not usually give a representative picture of the consumed proportion of different prey species when the prey types vary in size to a considerable extent. According to Floyd et al. and Ackerman et al. [21, 22], smaller prey species having more hair per unit body weight produce more scats per unit prey weight consumed, leading to an overestimation of smaller prey species in the carnivore diet. Hence, the correction factor developed by Ackerman et al. [22] was used to estimate the relative proportion of biomass of different prey species consumed by tigers in the study area. The regression of biomass consumed per scat produced against prey weight resulted in the linear relationship $Y=1.980+$ $0.035 X[22]$ has been used in the present study, where $Y=$ $\mathrm{kg}$ of prey consumed per field collectible scat and $X=$ average weight of an individual of a particular prey type. Solving the equation for $Y$ gave an estimate of biomass consumed per collectible scat for each prey type. Further, the relative biomass consumed (\%) and the relative number of individuals consumed (\%) were calculated; the data obtained are represented in Tables 1 and 2.

2.4. Study on the Diet of Captive Sundarbans Tigers. A comparative study on the dietary characteristics of Sundarbans tigers under captive situation, that is, within the premises of Calcutta Zoo, was also used to determine requirements and habits with regards to food of the Sundarbans tigers. The environmental conditions under which the Zoo tigers reside are purely artificial and the diet provided is restricted too. Each tiger is provided with $7 \mathrm{~kg}$ of beef every day with a weekly fast. So, the weekly biomass consumed by an adult tiger under such condition amounts to $42 \mathrm{~kg}$.

\section{Results}

From the above data, the mean biomass of each prey base species and percentage of relative biomass consumed in case of each of the prey base species have been used to calculate the average weekly consumption of the tiger in the wild during the two phases (Table 3). The results highlight the fact that the weekly average dietary requirement of the Sundarbans tiger whether in the wild or in captivity is similar.

Based on the data in Tables 1 and 2, a comparative analysis of the relative number of prey individuals consumed during phase 1 and phase 2 is graphically represented by a line plot in Figure 1.

The range of peaks for each prey base species in Figure 1 is indicative of difference in terms of the relative number of individuals consumed during the two phases, especially in the cases of the larger prey species-spotted deer, wild boar, and rhesus monkey. A hypothesis $\mathrm{H}_{01}$ was formulated based on

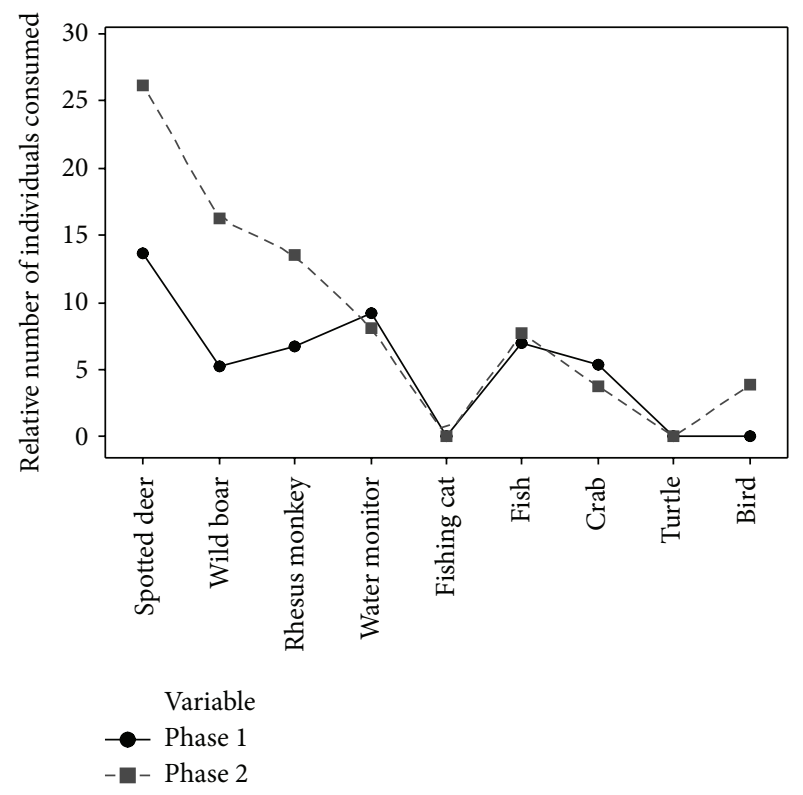

FIGURE 1: Comparative account of relative number of prey individuals consumed during phase 1 and phase 2 .

the assumption that there is no significant difference between the relative number of prey-base individuals consumed during the two phases. A paired $t$ test performed on the above assumption yields $t$ value $=2.54$ and an associated $P$ value $=0.035$ at $\alpha=0.05$. Thus, $\mathrm{H}_{01}$ is rejected, and a significant difference is established between the relative number of preybase individuals consumed by the Sundarbans tiger during the two phases over a temporal span of 10 years.

A similar hypothesis $\mathrm{H}_{02}$ was formulated based on the assumption that there is no significant difference between the relative biomass consumed by the Sundarban tiger during the two phases of study. A paired $t$-test performed on this assumption establishes the null hypothesis and $\mathrm{H}_{02}$ is accepted, implying that there is no significant difference in the relative biomass consumed by the Sundarbans tiger during the two phases of the study.

\section{Discussion}

An examination of the 214 scats (113 (phase 1) + 101 (phase 2)) led to the detection of 305 prey items in terms of occurrence (Tables 1 and 2). Spotted deer made up to $53.79 \%$ (phase 1) and $52.51 \%$ (phase 2) of all the prey items detected, but occurred in $69.02 \%-72.27 \%$ of all scat samples. Wild boar made up to $19.31 \%$ (phase 1) and $30.93 \%$ (phase 2), rhesus monkey $6.89 \%$ (phase 1) and 7.19\% (phase 2), and water monitor $9.65 \%$ (phase 1) and $4.31 \%$ (phase 2) of all the items detected in the collected scats. Fish, crab, and birds together contributed to only $9.63 \%$ (phase 1), 5.02\% (phase 2) of the detected items. Fishing cats and turtles were detected only once in the scat of the tiger, proving that they are not common dietary preference of the Sundarbans tigers. The leaves of Phoenix paludosa-a common mangrove palm of the Sundarbans was found to occur commonly in the scats that-are known to 
TABLE 1: Frequency of occurrence, estimated biomass consumed, and estimated numbers of individuals consumed by tigers in STR, based on the contents of scats collected from 1999 to $2001(n=113)$.

\begin{tabular}{|c|c|c|c|c|c|c|c|}
\hline Prey base & $\begin{array}{c}\text { No. of } \\
\text { occurrence in } \\
\text { scats } N_{\text {(occur) }}\end{array}$ & $\begin{array}{c}\text { Frequency of } \\
\text { occurrence }(\mathrm{A})\end{array}$ & $\begin{array}{c}\text { Percent } \\
\text { occurrence }\end{array}$ & $\begin{array}{l}\text { Mean body } \\
\text { mass/weight of } \\
\text { prey base (B) }\end{array}$ & $\begin{array}{c}\text { Correction } \\
\text { factor }(\mathrm{kg} / \mathrm{scat}) \\
(\mathrm{C})\end{array}$ & $\begin{array}{l}\text { Relative biomass } \\
\text { consumed (\%) } \\
\text { (D) }\end{array}$ & $\begin{array}{c}\text { Relative no. of } \\
\text { individual } \\
\text { consumed (\%) (E) }\end{array}$ \\
\hline Spotted deer & 78 & 69.02 & 53.79 & $50 \mathrm{~kg}$ & 3.73 & 63.16 & 13.62 \\
\hline Wild Boar & 28 & 24.77 & 19.31 & $45 \mathrm{~kg}$ & 3.55 & 21.57 & 5.29 \\
\hline Rhesus monkey & 10 & 8.84 & 6.89 & $8 \mathrm{~kg}$ & 2.26 & 4.9 & 6.70 \\
\hline Water monitor & 14 & 12.38 & 9.65 & $8 \mathrm{~kg}$ & 2.26 & 6.85 & 9.20 \\
\hline Fishing cat & 1 & 0.88 & 0.68 & $20 \mathrm{~kg}$ & 2.68 & 0.05 & 0.0002 \\
\hline Fish & 6 & 5.30 & 4.13 & $2.5 \mathrm{~kg}$ & Not corrected & 1.30 & 7.02 \\
\hline Crab & 7 & 6.19 & 4.82 & $0.2 \mathrm{~kg}$ & Not corrected & 1.08 & 5.37 \\
\hline Turtle & 1 & 0.88 & 0.68 & $15 \mathrm{~kg}$ & 2.50 & 0.05 & 0.0003 \\
\hline Phoenix paludosa & 14 & 12.38 & & & & & \\
\hline Total & 159 & & & & & & \\
\hline
\end{tabular}

(i) Frequency of occurrence (proportion of total scats in which an item was found).

Frequency of occurrence $=N_{i} \times 100 / N_{(\text {occur })}$.

(ii) Percent of occurrence (number of times in which a specific item was found as a percentage of all food items found barring Phoenix which is not considered as a conventional food item but is consumed by the tiger to regulate bowel movements).

Percent occurrence $=N i \times 100 / N_{\text {(occur.) }}-N_{(\text {Phoenix occur })}$.

( $N_{i}$ stands for number of times each species is found to occur in the scat samples).

TABLE 2: Frequency of occurrence, estimated biomass consumed, and estimated numbers of individuals consumed by tigers in STR, based on the contents of scats collected from 2008 to $2010(n=101)$.

\begin{tabular}{|c|c|c|c|c|c|c|c|}
\hline Prey base & $\begin{array}{c}\text { No. of } \\
\text { occurrence in } \\
\text { scats } N_{(\text {occur })}\end{array}$ & $\begin{array}{c}\text { Frequency of } \\
\text { occurrence (A) }\end{array}$ & $\begin{array}{c}\text { Percent } \\
\text { occurrence }\end{array}$ & $\begin{array}{l}\text { Mean body } \\
\text { mass/weight of } \\
\text { prey base (B) }\end{array}$ & $\begin{array}{c}\text { Correction } \\
\text { factor }(\mathrm{kg} / \mathrm{scat}) \\
(\mathrm{C})\end{array}$ & $\begin{array}{c}\text { Relative biomass } \\
\text { consumed (\%) } \\
\text { (D) }\end{array}$ & $\begin{array}{c}\text { Relative no. of } \\
\text { individual } \\
\text { consumed (\%) (E) }\end{array}$ \\
\hline Spotted deer & 73 & 72.27 & 52.51 & $50 \mathrm{~kg}$ & 3.73 & 58.17 & 26.24 \\
\hline Wild Boar & 43 & 42.57 & 30.93 & $45 \mathrm{~kg}$ & 3.55 & 32.61 & 16.28 \\
\hline Rhesus monkey & 10 & 9.9 & 7.19 & $8 \mathrm{~kg}$ & 2.26 & 4.82 & 13.57 \\
\hline Water monitor & 06 & 5.94 & 4.31 & $8 \mathrm{~kg}$ & 2.26 & 2.89 & 8.14 \\
\hline Fish & 04 & 3.96 & 2.87 & $2.5 \mathrm{~kg}$ & Not corrected & 0.85 & 7.69 \\
\hline Bird & 02 & 1.98 & 1.43 & $2.5 \mathrm{~kg}$ & Not corrected & 0.42 & 3.84 \\
\hline Crab & 01 & 0.99 & 0.72 & $0.2 \mathrm{~kg}$ & Not corrected & 0.21 & 3.75 \\
\hline Phoenix paludosa & 07 & 6.93 & & & & & \\
\hline Total & 146 & & & & & & \\
\hline
\end{tabular}

(i) Frequency of occurrence (proportion of total scats in which an item was found).

Frequency of occurrence $=N_{i} \times 100 / N_{\text {(occur) }}$.

(ii) Percent of occurrence (number of times a specific item was found as a percentage of all food items found barring Phoenix which is not considered as a conventional food item but is consumed by the tiger to regulate bowel movements).

Percent occurrence $=N_{i} \times 100 / N_{\text {(occur.) }}-N_{\text {(Phoenix occur) }}$.

( $N_{i}$ stands for number of times each species is found to occur in the scat samples).

be part of the tiger diet to help it regulate bowel movements. Most prey species that are common in the study area, both nocturnal and diurnal, were represented in the diet. A better estimate of the numerical importance of the various prey items in the diet could be calculated using a correction factor [22]. This gave an estimate of the number of collectible scats produced per animal consumed. The results reveal that though spotted deer contributes to about $65-75 \%$ of the tiger diet as biomass, it is only $13.62 \%$ (phase 1 ) $-26.64 \%$ (phase 2) of the relative number of individuals of all the prey base species consumed by the tiger. Interestingly, it is the smaller animals including the water monitors, birds, crabs, and fish that gain importance as part of the tiger diet than suggested by the uncorrected sample and contribute $21.59 \%$ (phase 1)$23.42 \%$ (phase 2) of the individuals consumed by the tiger in the wild. Thus, the ecological significance of the study lies in that the Sundarbans tiger exploits a wider range of available prey sizes to suit and fulfil its dietary requirements.

Furthermore, an analysis of the results obtained in the two different phases highlights a significant difference in terms of the number of individual prey base species consumed by the tiger within the Protected Area of Sundarbans Tiger Reserve. 
TABLE 3: Average weekly contribution of different prey base species to tiger diet in the Sundarbans Tiger Reserve area during the two different phases of study and weekly consumption of the Sundarbans tiger within zoo.

\begin{tabular}{|c|c|c|c|c|c|}
\hline \multirow[t]{2}{*}{ Prey base } & \multicolumn{2}{|c|}{$\begin{array}{c}\text { (Kg/week) and } \% \text { contribution to tiger diet } \\
\text { Phase } 1\end{array}$} & \multicolumn{2}{|c|}{$\begin{array}{c}\text { (Kg/week) and } \% \text { contribution to tiger diet } \\
\text { Phase } 2\end{array}$} & \multirow{2}{*}{$\begin{array}{l}\text { Mean weekly } \\
\text { consumption of } \\
\text { Sundarban tiger in Zoo }\end{array}$} \\
\hline & Biomass (kg/week) & Biomass \% & Biomass (kg/week) & Biomass \% & \\
\hline Spotted deer & 31.5800 & 74.69 & 29.0850 & 65.49 & \multirow{9}{*}{$\begin{array}{l}7 \mathrm{~kg} \text { of beef } \times 6 \text { days }+1 \\
\text { day fast }\end{array}$} \\
\hline Wild Boar & 9.7060 & 22.95 & 14.6740 & 33.04 & \\
\hline Rhesus monkey & 0.3920 & 0.927 & 0.3850 & 0.866 & \\
\hline Water monitor & 0.5480 & 1.296 & 0.2310 & 0.520 & \\
\hline Fishing cat & 0.0100 & 0.023 & 0.0000 & 0.000 & \\
\hline Fish & 0.0325 & 0.076 & 0.0212 & 0.047 & \\
\hline Crab & 0.0021 & 0.004 & 0.0004 & 0.0009 & \\
\hline Turtle & 0.0075 & 0.017 & 0.0000 & 0.000 & \\
\hline Bird & 0.0000 & 0.000 & 0.0105 & 0.033 & \\
\hline Total (kg) & 42.28 & & 44.41 & & 42.00 \\
\hline
\end{tabular}

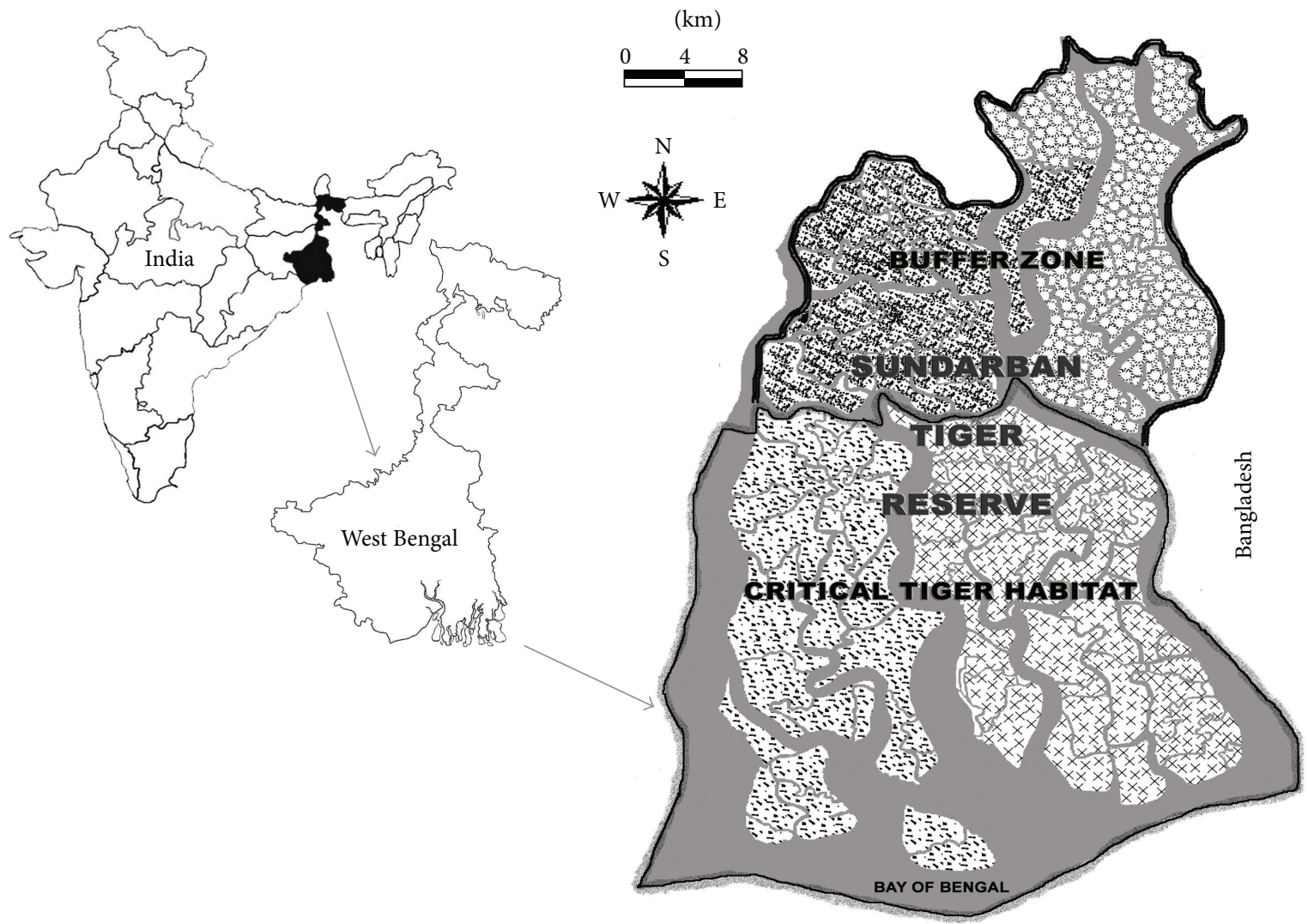

Estuarine rivers
Buffer zone
Critical Tiger habitat
Sajnekhali Wildlife Sanctuary (SWLS) range

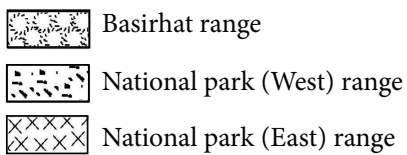

Figure 2: Sundarbans Tiger Reserve Area in West Bengal, India, showing the critical tiger habitat, Buffer area, and different protection ranges. 


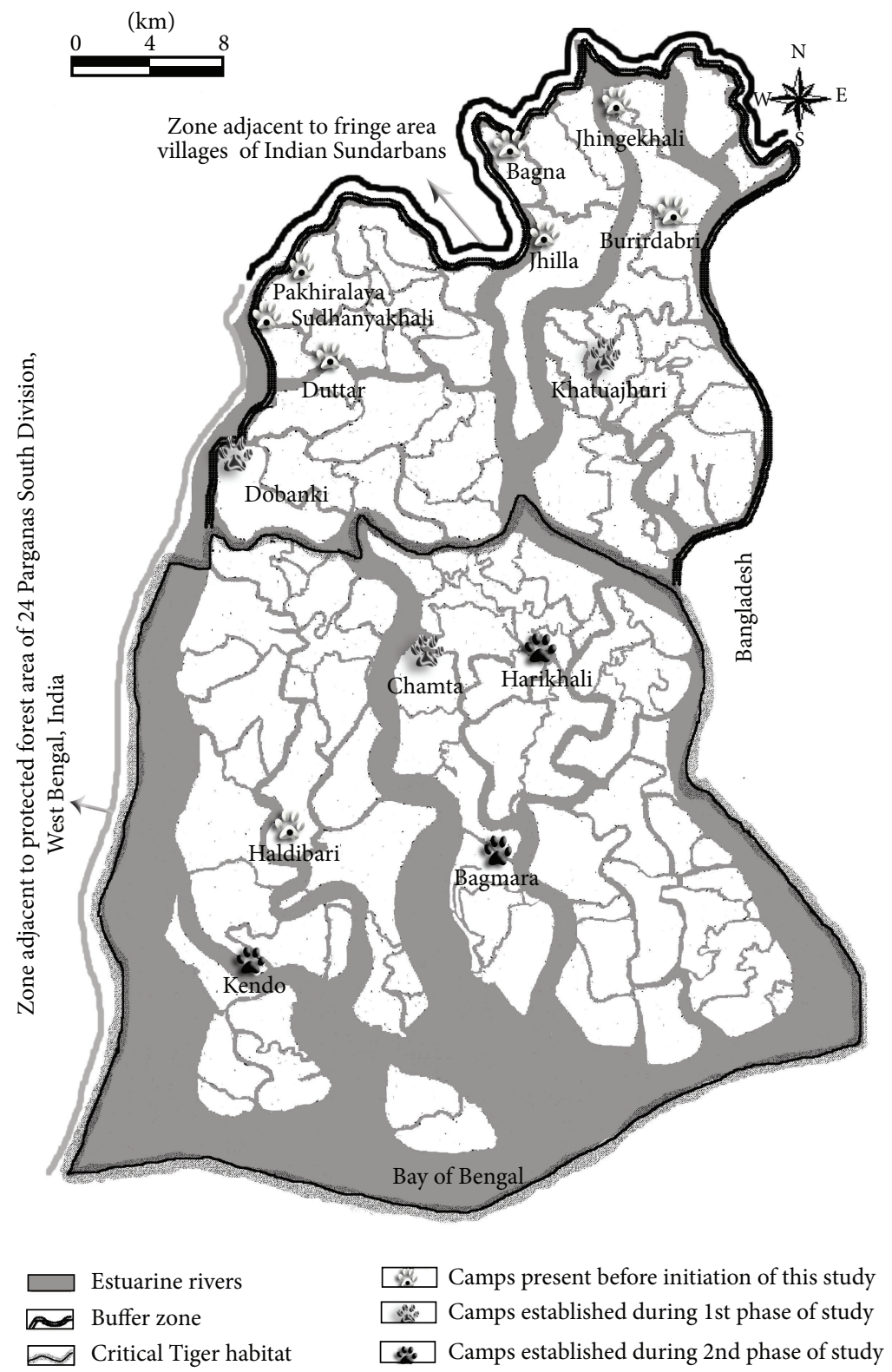

FIGURE 3: Protection camp locations within Sundarbans Tiger Reserve, before and during the study period.

This implies an increased prey availability for the tiger which can be interpreted as a direct effect of increased protection and vigilance initiatives implemented by the Department of Forest, within the area. The secondary data obtained from the Annual Reports of the Sundarbans Tiger Reserve validate such claims. The initiatives include intensification of management, increase in patrolling, regular monitoring programmes, employment generation for fringe area population specially in the ecotourism sector, distribution of administrative units over large areas as compared to the previously existing units situated very near to fringe villages, increase in number of land-based camps, introduction of floating camps and check posts, and stringency in issuance of tourist permits. A summary of the directly related protection activities initiated and implemented in terms of protection and vigilance during the two different phases of study is highlighted in Figure 3. These initiatives clearly emphasize the role that habitat protection has shown on the conservation of the Sundarbans tiger and its prey base.

\section{Acknowledgments}

The authors acknowledge the support and cooperation extended to them by the officers and staff of the Directorate of Forests, Government of West Bengal, during both phases of the present investigation. The authors also acknowledge the support and facilities extended to them by the National Fellow Laboratory of the Central Inland Fisheries Research Station for undertaking the research during the first phase of 
this present study. Further, the second author acknowledges the grant received from DST-PURSE to the University of Kalyani, West Bengal, India, during the final tenure of this study.

\section{References}

[1] A. Sih and B. Christensen, "Optimal diet theory: when does it work, and when and why does it fail?" Animal Behaviour, vol. 61, no. 2, pp. 379-390, 2001.

[2] A. Sih, P. Crowley, M. McPeek, J. Petranka, and K. Strohmeier, "Predation, competition, and prey communities: a review of field experiments," Annual Review of Ecology and Systematics, vol. 16, pp. 269-311, 1985.

[3] E. R. Pianka, "Competition and niche theory," in Theoretical Ecology, R. M. May, Ed., pp. 167-196, Blackwell Scientific, Oxford, UK, 2nd edition, 1981.

[4] G. B. Schaller, The Deer and the Tiger. A Study of Wildlife in India, The University of Chicago Press, Chicago, Ill, USA, 1967.

[5] A. J. T. Johnsingh, "Large mammalian prey-predators in Bandipur," Journal of the Bombay Natural History Society, vol. 80, no. 1, pp. 1-57, 1983.

[6] A. J. T. Johnsingh, "Prey selection in three large sympatric carnivores in Bandipur," Mammalia, vol. 56, no. 4, pp. 517-526, 1992.

[7] M. E. Sunquist, "The social organization of tigers (Panthera tigris) in Royal Chitwan National Park, Nepal," Smithsonian Contribution To Zoology, vol. 336, pp. 1-98, 1981.

[8] K. U. Karanth, "Estimating tiger Panthera tigris populations from camera-trap data using capture-recapture models," Biological Conservation, vol. 71, no. 3, pp. 333-338, 1995.

[9] J. Seidensticker, S. Christie, and P. Jackson, Eds., Riding the Tiger: Tiger Conservation in Human-Dominated Landscapes, Cambridge University Press, Cambridge, UK, 1999.

[10] D. Griffiths, "Prey availability and the food of predators," Ecology, vol. 56, pp. 1209-1214, 1975.

[11] D. W. Stephens and J. R. Krebs, Foraging Theory, Princeton University Press, Princeton, Mass, USA, 1987.

[12] E. Curio, The Ethology of Predation. Zoophysiology and Ecology, vol. 7, Spinger, New York. NY, USA, 1970.

[13] R. J. Taylor, "Value of clumping to prey and the evolutionary response of ambush predators," American Naturalist, vol. 110, pp. 13-29, 1976.

[14] S. A. Temple, "Do predators always capture substandard individuals disproportionately from prey populations," Ecology, vol. 68, no. 3, pp. 669-674, 1987.

[15] C. Packer, "The ecology of sociability in felids," in Ecological Aspects of Social Evolution, D. I. Rubenstein and R. W. Wrangham, Eds., pp. 429-451, Princeton University Press, 1986.

[16] M. E. Sunquist and F. Sunquist, "Ecological constraints on predation by large felids," in Carnivore Behaviour, Ecology and Evolution, J. L. Gittleman, Ed., pp. 283-301, Cornell University Press, Ithaca, New York, USA, 1989.

[17] M. V. Shirbhate, "Quantification of predation and incidence of parasitic infestation in Melghat Tiger Reserve with special reference to leopards (Panthera pardus)," The Bioscan, vol. 2, no. 1, pp. 41-46, 2007.

[18] J. A. Estes, D. O. Duggins, and G. B. Rathbun, "The ecology of extinctions in kelp forest communities," Conservation Biology, vol. 3, no. 3, pp. 252-264, 1989.
[19] F. Palomares, P. Gaona, P. Ferreras, and M. Delibes, "Positive effects on game species of top predators by controlling smaller predator populations: an example with lynx, mongooses, and rabbits," Conservation Biology, vol. 9, no. 2, pp. 295-305, 1995.

[20] L. Liebenberg, Tracks and Tracking in Southern Africa, Struik, Cape Town, South Africa, 2000.

[21] T. J. Floyd, L. D. Mech, and P. J. Jordan, "Relating wolf scat contents to prey consumed," Journal of Wildlife Management, vol. 42, pp. 528-532, 1978.

[22] B. B. Ackerman, F. G. Lindzey, and T. P. Hemker, "Cougar food habits in southern Utah," Journal of Wildlife Management, vol. 48, no. 1, pp. 147-155, 1984. 

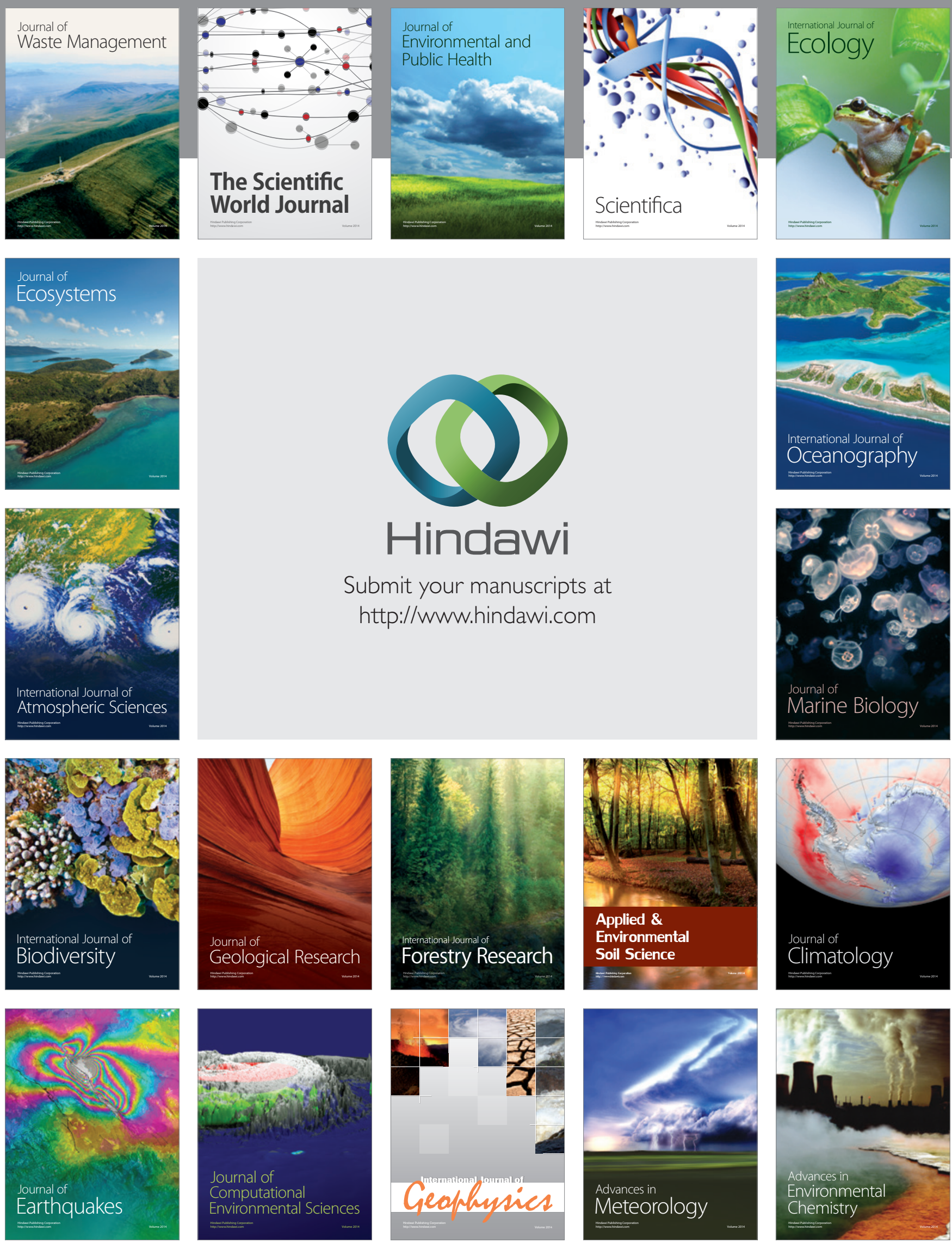